\title{
La subalternidad en la novela Eclipse de luna*
}

\author{
Alexis Uscátegui Narváez ${ }^{1}$ \\ Universidad Mariana (Colombia)
}

Referencia formato APA: Uscátegui-Narváez, A. (2014). La subalternidad en la novela Eclipse de luna. Revista Cientifica Guillermo de Ockham, 12(2), 111-116.

\section{Resumen}

El presente artículo es un trabajo investigativo que busca, a través de la teoría de la subalternidad, repensar la historia de aquellas personas consideradas como subalternos ante la sociedad latinoamericana. Entre manos, el presente documento destaca los aportes socioculturales de dos etnias: la indígena y la afrodescendiente, representadas por los protagonistas de Eclipse de luna, quienes, por cuestiones del destino, afrontan un apasionante universo de amor, dolor y muerte. En términos claves, erguido con firmeza sobre dichos supuestos el escritor colombiano Estupińán expresa con su novela la dolorosa y cruda verdad de la subalternidad en Nariño y el desarraigo y la miseria en Cumbal y Barbacoas.

Palabras clave: Subalternidad, novela, subalterno, escritor, hegemonía

\section{The subalternity theory within the novel eclipse de luna}

\section{Abstract}

This paper is an investigative work that seeks, through literary criticism and textual interpretation, rethinking the history of those who are considered as subalterns to the Latin American society. Between hands the present document, highlights the cultural contributions of two races (indigenous and Afro-descendant) represented by the protagonists of Eclipse de luna, who for reasons of fate are facing a fascinating universe of love, pain and death. In key terms, Estupiñán erect with firmness on these assumptions, expressed with his novel, the raw and painful truth of subalternity in Nariño, rootlessness and misery of Cumbal and Barbacoas.

Keywords: Subalternity, novel, subaltern, writer, hegemony

* El presente artículo teórico es el resultado de la investigación Los subalternos en la novela Eclipse de luna, de Ricardo Estupiñán Bravo, adscrita al Grupo de Investigación Forma de la Universidad Mariana. Fecha de inicio 20 de abril de 2013. Fecha de finalización septiembre 05 de 2014.

1. Licenciado en Lengua Castellana y Literatura. Magíster en Etnoliteratura e integrante del grupo de investigación Forma, de la Universidad Mariana. Dirección postal. Calle 18 N³4-104 Pasto-Colombia. E-mail: auscategui@umariana.edu.co 


\section{Introducción}

Las teorías de la subalternidad han dejado una huella inquebrantable con respecto a la legitimación y liberación del otro (el negro, el homosexual, el indio, la mujer, el anciano, el pobre y el mendigo, entre otros) ante el eurocentrismo y el anglocentrismo, y su propósito no es otro que ubicar a estas personas en un componente sociocultural digno, porque cada una de ellas aporta al bienestar y al desarrollo de un determinado Estado. Al hacer una relectura crítica a la sociedad latinoamericana, se hace evidente el hecho de que se ha liberado al subalterno de manera física, mas no de pensamiento. Es decir, la colonialidad (término totalmente diferente a colonialismo), aún no termina. Restrepo y Rojas (2010), establecen que el colonialismo

Refiere al proceso y los aparatos de dominio político y militar que se despliegan para garantizar la explotación del trabajo y las riquezas de las colonias en beneficio del colonizador. La colonialidad, en cambio, es un fenómeno mucho más complejo que se extiende hasta nuestro presente y se refiere a un patrón de poder que opera a través de la naturalización de jerarquías territoriales, raciales, culturales y epistémicas, posibilitando la reproducción de relaciones de dominación; este patrón de poder no solo garantiza la explotación, sino también la subalternización y obliteración de los conocimientos, experiencias y formas de vida de quienes son así dominados y explotados (p. 15).

En estas condiciones, la novela Eclipse de luna de Ricardo Estupiñán Bravo $^{2}$ es una narración que contempla distintos parajes significativos de acuerdo con su temática central: la subalternidad, sin dejar de lado otros aspectos como el amor, el dolor y la muerte. Muchos se preguntarán el porqué de retomar procesos minoritarios en la actualidad si la colonia ya "terminó" hace mucho tiempo; sin embargo, tendríamos que dar respuesta trágica al encontrar aún en las sociedades latinoamericanas, mandatos hegemónicos que si bien no subordinan -tal vez- físicamente a sus servidores, sí lo hacen de forma conceptual, ideológica y religiosa y como ejemplo de ello se puede hacer valer el hecho de que los indios y los afrodescendientes no son tenidos en cuenta para la construcción de un Estado. Joaquín Senderos, uno de los protagonistas de la novela, es un indio proveniente del bello paisaje que rodea al municipio de Cumbal, localidad ubicada al sur del departamento de Narińo y asentada junto al Macizo Colombiano. Es una región fría cuya temperatura no rebosa los nueve grados centígrados y en ella Joaquín trabaja arduamente como hielero para sacar a su familia adelante. El nevado de Cumbal es un cerro, considerado por Guerrero (1998) "como un gigante de la cordillera de los Andes; alcanza los 4.890 metros sobre el nivel del mar y de sus entrañas se extrae azufre para uso doméstico y hielo para un pequeño comercio interregional" (p. 23).

Yemeyá, por su parte, lucha día a día para obtener algunas migajas de oro en su tierra natal, Barbacoas, municipalidad de Nariño que se encuentra

Incrustada en la zona verde montañosa, en las estribaciones de la Cordillera Occidental de los Andes, con unos 28 grados de temperatura. Los ríos que rodean la región son limpios y guardan en su lecho invaluables cantidades de oro de finísimo quilate; entre sus ríos más afluentes está el Telembí (Guerra 1980, p. 8).

La ascendencia de Yemeyá proviene del África, un continente que lucha por su revaloración cultural y social, rompiendo los paradigmas racistas impuestos por las ideologías neocoloniales. Esta barbacoana ostenta, sin duda alguna, esa riqueza ancestral africana plena de un etos de costumbres, tradiciones, mitos y leyendas explícitas en varios capítulos de Eclipse de luna. Si bien la raza negra ha sido opacada conceptualmente, intelectuales de la talla de José Martí y Nelson Mandela han luchado por la dignidad de los afros. En términos de Oswald de Andrade (1981) fueron unos antropófagos de los pensamientos occidentales que lideraron procesos de lucha universal para liberar a los oprimidos, a los subalternos que vivieron como esclavos durante muchos ańos enriqueciendo la industria burguesa.

La explotación colonial se extendió también por Nariño, donde poblaciones como Barbacoas padecieron incontables abusos. La novela de Estupiñán refleja, precisamente, las labores impuestas por los colonos: minería, agricultura, construcción y servicio doméstico, entre otras, oficios únicos que se vieron obligados a hacer sus habitantes debido a la desigualdad social, lo que generó por siglos una cruel estigmatización que los marcaba como seres inferiores y fue causa de brutales genocidios que buscaban acabar con la población negra e indígena. La opresión colonial persiste en la actualidad inmersa en los procesos socioculturales (Fanon, 1963). Este dominio es simplificador, desintegra la las culturas y la ley tribal, niega al afro y al indígena como miembros de un grupo

2. Ricardo Estupiñán nació en Cumbal en 1959 y fue dirigente del M-19 en Nariño. Es Abogado de la Universidad de Nariño con estudios en Administración Agropecuaria en la Universidad de la Salle en Bogotá. Especialista en Derecho Financiero de la Universidad del Rosario, ha sido asesor de cabildos indígenas, alcaldías y de la Asamblea Departamental de Nariño. Dentro de su creación literaria ha publicado los libros La tierra de los cumbales (2002), Caminando por el sur (2003) y la novela Eclipse de luna (2011).

$112<$ Universidad de San Buenaventura, Cali - Colombia 
social, rechaza sus costumbres e imaginarios y trata de obliterar su estructura biológica sobre la base de que lo blanco es lo predominante. Por ello es necesario volver a escribir la historia.

\section{Fundamentos subalternos}

Con base en distintas teorías, se elaboró un marco conceptual que permitió el análisis y la interpretación de la novela Eclipse de luna, con postulados que tienen en cuenta los procesos pluriétnicos de los "subalternos". El marco dinamiza la labor individual y social de los grupos minoritarios en cuestión, proyecta la legitimación del otro, critica las hegemonías y busca la transformación de la realidad social.

La subalternidad es una de las teorías postcoloniales más significativas dentro de la historia sociocultural y literaria, al manifestar diversos aspectos que revaloran los discursos considerados como minorías. El historiador indio Ranajit Guha reformuló la historiografía de los pueblos colonizados y excluidos por el discurso eurocentrista, devolviéndoles así su valor social. La subalternidad se origina a finales del siglo XX en India y es utilizada por Guha (2002) para referirse a los discursos hegemónicos que dominan a los subalternos (movimientos de insurgencia campesina). Más adelante, el mismo autor se atribuye el término para plasmar el carácter general de subordinación en la sociedad del sureste asiático y exponer sus ideas renovadoras, a fin de rescatar las voces subalternas silenciadas por la historia oficial.

Respecto a la subalternidad en Latinoamérica, el Grupo de Estudios Subalternos se ha encargado de estudiar la manera como confluyen las prácticas hegemónicas en el continente. En esta línea, Castro y Mendieta (1998), sostienen que la subalternidad "es, por lo tanto, el nombre de los varios puntos de exceso dentro de las historias nacionales y posnacionales del desarrollismo latinoamericano" (p. 8).

Desde esta perspectiva, al escudriñar el contenido literario de Eclipse de luna se puede hallar una relación mutua entre los estudios subalternos y el eje central que constituye el argumento de la novela, puesto que los dos personajes principales son estigmatizados como "minorías" por sus trabajos y formas de vida que los enmarcan en ese procedimiento subalternizante, a pesar de que Joaquín y Yemeyá cumplen otro tipo de funciones que son dignas de valorarse en los procesos culturales y sociales del país y Latinoamérica. La subalternidad "es un fenómeno de diseminación ideológica de una categoría englobante y homogeneizadora por la que se intenta abarcar a todos aquellos sectores subordinados ante los discursos y praxis del poder" (Moraña, 1998, p. 180). En relación con el vocablo subalterno Moraña aclara lo siguiente:

El término aparece incluido para hacer referencia a los desposeídos y marginalizados por el régimen colonial, pero la connotación denigratoria del término impide utilizarlo como interpelación de los vastos sectores a los cuales debe abarcar el utopismo de la emancipación. En las teorizaciones actuales, el concepto de subalternidad se vuelve a potenciar a partir de la elaboración gramsciana, en la cual el marxista italiano hace referencia a los estratos populares que ante la unidad histórica de las clases dirigentes, se hacen presentes a través de una activación episódica, presentándose como un nivel disgregado y discontinuo con grados variables y negociados de adhesión a los discursos y praxis hegemónicos (p. 180).

Se puede afirmar que los regímenes colonial y poscolonial fueron una "vanguardia" ideológica de poder que jerarquizó de manera minoritaria los discursos subalternos e impidieron la emancipación de sus concepciones y pensamientos ideológicos; esto es, dichos sistemas pretendieron homogeneizar una ideología que unificara el movimiento y los propósitos que estos sistemas sostienen. En Eclipse de luna están inmersos algunos de estos aspectos; por ejemplo, al revisar minuciosamente varios capítulos de la novela, se pueden encontrar prácticas de explotación humana en Barbacoas con respecto a la extracción de oro. La novela se recrea en una geografía donde la raza negroide revela siglos de historia con relación a la subalternidad. Luego de la llegada de los españoles, las comunidades afro padecieron innumerables carencias a pesar de que tenían todo el oro a su disposición y fueron explotados de manera inhumana en diversos trabajos. Estupiñán (2011) manifiesta: "Barbacoas ha sido la despensa aurífera de América. Desde 1556, cientos de libras de oro se enviaron a la monarquía ibérica" (p. 59).

En esta medida, Estupiñán señala que los esclavos de Barbacoas recibían su respectivo pago solo si llenaban una totuma de oro cada día. Esto encierra una ironía descomunal, ya que esta tierra del oro y la libertad sobrevivió encadenada a la miseria y en precarias condiciones.

De este modo, se podría afirmar que las hegemonías (los españoles), subalternizaban a los indios ${ }^{3}$ y negros, esclavizándolos con la explotación del mineral dorado.

3. Se hace referencia a los indios, porque en Barbacoas habitaron distintas comunidades indígenas, como los sindaguas, los telembíes, los barbacoas, los iscuandés y los tapajes. 
Por tal razón, los subalternos (afrodescendientes, indios, negros, campesinos, mujeres, entre otros) promovieron un movimiento categórico migrante que se expandió por la sociedad en busca de sus propios ideales, llevando a cabo de esta manera una revolución ideológica que consagraría sus propias facultades físicas y mentales dentro de la sociedad. El "boom del subalterno" se podría denominar como hipótesis de esta causa que Moraña (1998) más adelante reconoce:

El boom hace alusión al montaje ideológico-conceptual que promueve la subalternidad como parte de una agenda exterior, vinculada a un mercado donde aquella noción se afirma como un valor de uso e intercambio ideológico y como marca de un producto que se incorpora, a través de diversas estrategias de promoción y reproducción ideológica, al consumo cultural globalizado. En un segundo nivel, la expresión se refiere al modo en que las relaciones de subordinación (explotación, sujeción, marginación, dependencia) político-social, se transforman en campo de conocimiento, o sea se re-producen como objeto de interpretación y espacio de poder representacional (p. 181).

Desde este punto de vista, el sujeto subalternizado ha liberado sus opresiones ideológicas que el poder colonizador le impuso. Ahora, su principal propósito es buscar sus formas independientes de vivir y pensar dentro de una sociedad heterogénea, multiculturalista y pluriétnica y en este sentido, se enmarca el enamoramiento de Joaquín con Yemeyá, quienes a pesar de provenir de dos razas diferentes unen su sangre por medio de un eclipse metafórico fruto del amor y la pasión.

En Eclipse de luna, se observa que Joaquín trabaja fuertemente junto con su familia y arriesga su propia vida escalando el nevado de Cumbal para obtener algunos trozos de hielo y así solventar sus necesidades económicas. "Somos hieleros del silencio, muriendo en vida sobre un volcán vestido de invierno y rematado de nevisca que exhala humaredas de azufre en espirales retumbantes" (Estupiñán, 2011, p. 15). El padre de Joaquín, conocido como Papá señor, es una persona de la tercera edad que por su trabajo como hielero no presenta una salud favorable; sin embargo, su espíritu es fuerte y el amor que siente por sus hijos hace que siga viviendo el día a día. Al igual que sus progenitores, Papá señor fue un subalterno más de la región y desde su infancia trabajó arduamente para servir a los españoles y vasallos que se encargaban de obtener riquezas a costillas de sus súbditos:

Cuando yo era guambra, acompañaba a mi papacito con las recuas a Barbacoas; nos demorábamos quince días a pata limpia, caminábamos hasta dieciséis horas diarias, descansábamos en las pascanas; mi papacito jalaba las bestias abarrotadas de quesos, papas, cobijas de lana, carne salada, cebada. De vuelta a Túquerres, cargábamos las mercancías de los barcos de vapor que venían del Pacífico por el Patía, el Telembí; esas naves traían pianos, molinos, muebles, vinos, enlatados, lámparas, calzado, vasijas. También trasportábamos oro y platino de Barbacoas. Todo a lomo de mula. En una ocasión mi papacito soportó en su espalda al cura español Fabián Guarísti Locadio, flaco, alto, blanco y muy simpático (...) Los señores blancos iban montados en los lomos de los indios y de los negros. Los negros ya eran libres, pero seguían sirviendo (Estupiñán, 2011, pp. 20-21).

Conviene tener en cuenta que la subalternidad está ineludiblemente ligada al argumento de la novela, ya que el autor no oculta la cruel historia que vivieron los cumbaleños en épocas anteriores, a pesar de la bonanza y la gran cantidad de oro que había para extraer en Barbacoas. Los indios y los negros que trabajaban para sus amos "decían que los ricos comían oro con plátano maduro y los pobres escarbaban la mierda” (p. 22). No obstante, a pesar de su padecimiento Joaquín es obstinado y continúa trabajando por su familia y al igual que cualquier otra persona también se enamora del hermoso paisaje de su comarca, de la música barbacoana, de las tradiciones negroides y, por supuesto, de la mujer que considera la más hermosa de la región pacífica: Yemeyá.

No existe, pues, una alteridad vivencial entre ambos supuestos (subalterno-criollo), por lo cual el sujeto imperioso controla al subalterno y busca solo la satisfacción de sus intereses individuales para un determinado fin dogmático. Ahora, si ubicamos este supuesto en el contexto de Nariño, su cultura afrodescendiente, su música y sus tradiciones populares, revelan un acervo ancestral que diferencia esta región de cualquier otra de la circunscripción. En Barbacoas, por ejemplo, la calidez no solo alude a su clima, sino también al modo de ser de su gente, cálida y amigable. En esta zona, se desarrolla entre sus panoramas y sucesos de vida, uno de los pasajes más esenciales de la novela. Ella, Yemeyá, es una joven profesora que recolecta oro del río Guelmambí y se constituye en uno de los estereotipos de mayor trascendencia en este municipio. Es, asimismo, una mujer que disfrutó al máximo su vida, amó su raza, su familia, su gente y a Joaquín.

A partir de esta circunstancia, los estudios subalternos se constituyen en una cosmovisión histórica sobre la rebelión de capital importancia para la comprensión de los grupos y clases minoritarios como sujetos de su propia historia y quienes, sin lugar a dudas, tienen derecho de proponer sus atributos ante una determinada sociedad. A esto se suma que en cualquier comunidad social subsisten políticas de dominación que pretenden opacar la entidad 
subalterna, una discriminación en busca de la raza dominante que se acompaña de discursos de poder (burocracia) en contra de estos grupos subalternizados. Gracias a los estudios subalternos, se ha logrado comprender la revolución ciudadana y a través de estas conjeturas realizadas diacrónicamente, la subalternidad ha permitido involucrarlos nuevamente como seres de una historia universal.

En Eclipse de luna subyace la intención de estudiar los procesos colonizadores en el continente americano, de ahí los estudios poscoloniales en América Latina fueran formalizados con la creación del Grupo de Estudios Subalternos, fundado por Guha (2002), quien utilizó el concepto de subalternidad para dar una nueva lectura a los textos pertenecientes al período colonial y como una crítica a la erudición histórica que "desde los primeros grados de escolaridad institucionalizaron cánones y narratologías que promovieron la hegemonía [...] Era necesario rescribir la historia siguiendo la voz de una subalternidad desafiante y comprometida a escribir su propia historia" (pp. 31-32). Este grupo se fijó como objetivo principal, salvaguardar la reconstrucción histórica de las voces consideradas minoritarias y marginadas por las prácticas oficiales. La crítica de este colectivo fue refutar los ilógicos discursos elitistas que irrumpían la semiótica social y cultural de los subalternos.

La literatura, entonces, abarca esos procesos culturales y contribuye a la historia social de cada región y en esta vía, Eclipse de luna distingue la esencia multicultural de dos razas que aportan a la cultura nariñense. Nicolás del Castillo Mathieus, en el prólogo de La saga del negro de Friedemann (1993) aclara que

[...] a los negros del Pacífico se les han ignorado sus aportes culturales; casi no sabemos nada de sus modos de actuar, pensar, y vivir, ocultando que toda esta población afroamericana también es digna de participar en las prácticas culturales de la nación colombiana (pp. 11-15).

Por esta razón, la novela rescata parte de aquellos valores propias del departamento de Narińo y sobre esta base, Bueno (2004) destaca el hecho de que la literatura está ligada profundamente a los problemas culturales, puesto que luego de una larga historia colonial aún se conservan discursos neocoloniales o hegemónicos que impiden que dichas expresiones artísticas trasciendan en un determinado contexto; o sea, se establece una heterogeneidad literaria, mas no se valora la subalterna. En palabras del autor "[...] ello conduce a enfocar las culturas como conjuntos estructurados de imágenes dinámicas del mundo (el individuo, el grupo, el medio, sus relaciones), y como encuentros y negociaciones de sistemas bastante dispares y en conflicto" (p. 121). Precisamente, lo que aclara Bueno en el anterior planteamiento es lo que Estupiñán desea rescatar en su obra, sobre todo cuando critica el sistema administrativo de Narińo con respecto al mal servicio público.

En efecto, dentro de los discursos hegemónicos el subalterno desempeña un papel importante, y en este sentido los estudios poscoloniales han marcado un sendero para que sus prácticas ideológicas tengan un espacio en la academia y en la cultura social. Ello significa que la perspectiva elitista cambió, como lo expresan Castro y Mendieta (1988):

Desde el momento en que los subalternos se encuentran atravesados por redes globales que los vinculan tanto a la metrópoli como a la periferia, así como por exclusiones de tipo económico, racial y sexual que operan más allá y más acá de la "nación" (p. 11).

En el ensayo Discurso colonial y teorías poscoloniales, los mismos autores explican cómo surgió la iniciativa de la revelación de las minorías ante los discursos hegemónicos y subalternantes:

La crítica se articuló desde metodologías afines a las ciencias sociales, las humanidades y la filosofía, tal como éstas habían sido desarrolladas por la modernidad europea desde el siglo XIX. De hecho, el logro de la modernidad se constituyó en el horizonte crítico-normativo de todos los discursos anticolonialistas. La dependencia económica, la destrucción de la identidad cultural, el empobrecimiento creciente de la mayoría de la población, la discriminación de las minorías, todos estos fenómenos eran considerados como "desviaciones" de la modernidad que podrían ser corregidas a través de la revolución y la toma del poder por parte de los sectores populares. Estos - y ya no la burguesía — serían el verdadero "sujeto de la historia"; los encargados de llevar adelante el proyecto de "humanización de la humanidad" y hacerlo realidad en las naciones colonizadas (Castro \& Mendieta, 1988, pp. 10-11).

Las denominadas teorías poscoloniales se proyectaron a los países del tercer mundo en busca de una reivindicación del pensamiento opacado por los sistemas del primer mundo -conocidos como regímenes elitistas- que pretendieron "destruir el legado cultural y la memoria colectiva de los subalternos" (Castro \& Mendieta, 1988, p. 12) y establecer sus propósitos etnocentristas. No obstante, muchos intelectuales del tercer mundo defendieron sus procesos culturales ante dicho supuesto social y contribuyeron a la emancipación de sus concepciones idealistas ante el mundo.

A pesar de todo, Latinoamérica padece en la actualidad los rigores del poder hegemónico recreado en las obras lite- 
rarias. Escritores como Ángel Rama, José María Arguedas y José Martí, entre otros, han criticado estas políticas de dominación y en esta dirección Estupiñán reflexiona sobre este tipo de fluctuaciones socioculturales. Bajtín (1989) resalta el valor de una obra de arte (literaria) en su contenido, cuando esta no es analizada de forma superficial:

Ver u oír algo, simplemente, no significa que se perciba ya la forma artística; es necesario para ello hacer de lo que se ha visto, oído o pronunciado, la expresión de nuestra actividad axiológica activa: es necesario participar como creador en lo que se ha visto, se ha oído, se ha pronunciado, y, por medio de ello, superar la materialidad, la determinación extra-artística de la forma, su realidad: la forma ya no está fuera de nosotros, como material percibido y organizado cognitivamente; se ha convertido en expresión de la actividad valorativa que penetra el contenido y lo transforma (p. 62).

El valor que cumple el "subalterno" en Eclipse de luna, se puede vislumbrar en el anterior planteamiento, dado que las obras literarias no pueden dejarse atrás sin un minucioso acto valorativo y requieren ser analizadas y percibidas a través de los sentidos para interpretar sus horizontes artísticos y crear un nuevo texto a partir de una lectura previa que, entre otros términos, es considerada como una crítica literaria. Sin ella, las obras no podrán trascender.

\section{Conclusiones}

Eclipse de luna sublima la riqueza etnoliteraria de $\mathrm{Na}-$ rińo por medio de su contenido narrativo: una historia que enmarca la historia, la belleza musical, la ficción, la oralidad, el amor, el dolor y la muerte. La novela de Estupiñán a través de una historia de amor y dolor en tierras nariñenses, revindica los padecimientos que aún viven el indio y el afrodescendiente y al interpretar su argumento se libera la posibilidad de la unión fraternal de la multiculturalidad de las razas.

La subalternidad, que choca con muros sensibles, es asunto que intranquiliza a Ricardo Estupiñán, tesis que resalta en su novela con tono decolonial. Cabe destacar que su ideal en el departamento de Narińo es buscar, a través de su crítica narrativa, la emancipación del subalterno. El tema central de Eclipse de luna se trasforma así en un reclamo social por vivir dignamente en lo que el Gobierno ha constituido como un Estado social de derecho. Este autor recorrió varios municipios del departamento y se dio cuenta de la fría realidad que viven un campesino, un afrodescendiente, un indio, un niño, una mujer y un anciano; extractos subalternos que son retomados en su obra como crítica sociocultural. También cabe afirmar que la influencia de la música andina y afroamericana ha inclinado la trama de su novela, pues su narrativa es un repertorio de la multiplicidad musical del continente que evoca temas como la libertad, el amor, el dolor y la muerte.

Por lo demás, escasos son los defectos de Eclipse de luna, pues en términos de Fanon (p.193), es una novela de combate que permite al lector ir más allá del grito liberador y convoca a todo el pueblo nariñense a la lucha por la existencia nacional, latinoamericana y universal y nos hace recordar que fuimos, somos y seremos siempre libres.

\section{Referencias}

Bajtín, M. (1989). Teoría y estética de la novela. Madrid: Editorial Taurus.

Bueno, R. (2004). Antonio Cornejo Polar y los avatares de la cultura latinoamericana. Lima: Universidad Nacional Mayor de San Marcos.

Castro, S., \& Mendieta. E. (Eds.). (1998). Teorías sin disciplina. Latinoamericanismo, Poscolonialidad y Globalización en debate. México: Miguel Ángel Porrúa.

De Andrade, O. (1981). Oswald de Andrade obra escogida. Recuperado de http://goo.gl/kIRdHx

Estupiñán, R. (2011). Eclipse de luna. Colombia: Edinar.

Fanon, F. (1963). Los condenados de la tierra. México: Fondo de la cultura económica.

Friedemann, N. (1993). La saga del negro. Colombia: Universidad Javeriana.

Guerra, G. (1980). Tierra del oro: Reseña histórica de Barbacoas. Pasto: Imprenta Departamental.

Guerrero, G. (1998). Estudios sobre el municipio de Cumbal. Bogotá: Internacional de Impresos El Dorado.

Guha, R. (2002). Las voces de la historia y otros estudios subalternos. Barcelona: Crítica.

Morańa, M. (1998). El boom del subalterno. En S. Castro \& E. Mendieta (Eds.), Teorias sin disciplina. Latinoamericanismo, poscolonialidad y globalización en debate (pp. 175-184). México: Miguel Ángel Porrúa.

Restrepo, E., \& Rojas, A. (2010). Inflexión decolonial: fuentes, conceptos y cuestionamientos. Colombia: Editorial Universidad del Cauca. 